this report the board confines itself to the period 1968-1975.

To put its views into practice, it recommends that relatively small and inexpensive unmanned spacecraft be launched to orbit Venus and Mars at each favourable conjunction (these occur at roughly 18-month intervals for Venus, and every 2 years for Mars). NASA should send spin-stabilized spacecraft of the reliable Pioneer and IMP types on planetary missions over the next 7 years, the board considers. It favours the diversion of existing Pioneer E craft to the exploration of Venus in 1970, with additional flights in 1972, 1973 and 1975. It also strongly supports a Pioneer mission to pass by Jupiter, the solar system's largest planet, in 1972 and 1973.

Because of the great importance of biological investigations of Mars, the report recommends a Mariner orbiter mission there in 1971, and a Marinercarried combination orbiter and lander in 1973. The proposed Mars missions and the small planetary spacecraft series are considered a "minimal programme"; but, the report asserts, "such a programme has greater priority both in terms of expected purely scientific returns and in long term benefits to society than other space ventures such as the qualifying of man for planetary voyages".

In both 1973 and 1975 a spacecraft on a fly-by mission to Venus could make use of the planet's gravitational field to be accelerated on to Mercury. Such an opportunity-which will not recur until the eightiesprompts the report to give second highest priority to this "two-for-one" mission. The fly-by would provide the first close photographs of Mercury and possibly reveal surface effects caused by the planet's proximity to the Sun. It will be interesting to see if the Space Sciences Board's new report has any more influence on the direction of the national programme than did the last one.

\section{Costly Phantom}

UNHaPPY decisions made by the Ministry of Aviation keep coming to light. Usually the Public Accounts Committee of the House of Commons has the sad task of publishing the details, and the latest report from the

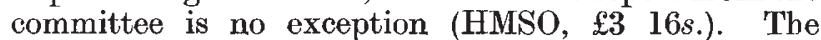
committee investigated two decisions in particular; one, to buy a small number of Beagle Basset aircraft and the other to fit the Rolls-Royce Spey engine into the American Phantom aircraft.

When the Royal Navy decided to buy the Phantom, it was already quite an old aircraft. Nearly 3,000 had been produced in the United States, but the Royal Navy had to have a more powerful version to enable the aircraft to take off from the shorter British aircraft carriers. It was therefore decided to fit the Spey engine into the Phantom, at a tentative development cost of $£ 25$ million. By the time a firm decision was

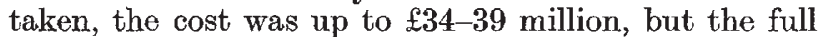
costed programme was not produced by Rolls-Royce until after the decision had been taken in February 1965 to buy the Spey Phantom for the Royal Air Force as well. By May 1965, the cost of developing the engine and modifying the airframe to fit the engine and take British electronic equipment for the Navy and the RAF was up to $£ 80-90$ million. When the costs of production in Britain are taken into account, the total cost of the anglicized Phantom is about 50 per cent more than the American version, and the unit cost of the 170 Phantoms which are being bought is almost twice the cost of the American version. In contrast, when the Hercules aircraft was bought from the US, the price paid was almost exactly the same as that paid by the American armed forces, because no expensive modifications were demanded.

The committee draws the obvious conclusions from this sorry story. When off the shelf purchases are made, the report says, the benefit of reduced costs arising from long production runs can be totally lost if the standard version is substantially modified. Unfortunately, there is less evidence that the RAF has learned its lession. Before the cancellation of the F11 a ircraft from the US, there were already signs that the cost of the aircraft was increasing because of RAF demands for British equipment to be installed.

The other PAC investigation tells an equally sad tale, which seems to have sprung from equally good intentions. In 1963 the RAF was persuaded by the Ministry of Aviation to buy a new aircraft, the Beagle Basset, in place of the slightly old-fashioned Devon. The role the Basset had to fill was for a communications aircraft and also as a transport for ferrying the crews of bombers about. But it soon became clear that the performance of the Basset was not all that had been hoped for; at high temperature there was a much greater decrease in engine power than had been expected. Although the RAF is prepared to accept safety standards lower than those acceptable for civil airlines, it became clear that either the payload or the range of the Basset was going to suffer. In fact, as the PAC found out, the Basset carrying five people has a range of 485 miles instead of 1,000 miles at $15^{\circ} \mathrm{C}$, and the seven seat version needed for transporting $V$ bomber crews has a reduced payload and a range reduced to 194 nautical miles at $15^{\circ} \mathrm{C}$. At $30^{\circ} \mathrm{C}$, the range of the seven seat version is reduced to nil, an unhappy situation for a $V$ bomber crew stranded somewhere hot. In part this failure was caused by the requirement of the RAF for more equipment than is normal in civil airliners; and it seems that the extra 300 pounds of equipment reduce the range by about 300 miles. Nobody denies that the Devon would have been better, though marginally more expensive $(£ 73,000$ against $£ 65,000$ each), but the Ministry of Aviation seems to have been motivated by the laudable aim of encouraging the development of small aircraft in Britain. The Ministry of Technology, in fact, continues to support the Beagle company, without so far producing much visible return.

\section{Nuclear Gas}

If preliminary results are any guide, Project Gasbuggy, the American experiment to increase the recovery of natural gas from rock formations of low permeability by fracturing the rock with a contained nuclear explosion, has been a success. The principle behind the experiment is, of course, well tried ; the normal practice in mining gas from sandstone formations is to drill the well and then fracture the gas-bearing strata either by forcing water into the rock or, more rarely these days, by exploding nitroglycerine at the bottom of the shaft. Gasbuggy, a joint venture of the US Atomic Energy Commission, the Department of the 
Interior, the Bureau of Mines and the El Paso Natural Gas Company, was the first attempt to scale up this procedure with a nuclear explosion.

A 26 kiloton device was exploded near Farmington, New Mexico, on December 10 last year at a depth of 4,200 feet, well below the maximum depth for conventional gas mining, and it produced a chimney in the rock with almost exactly the dimensions that had been predicted. The chimney, with a volume of at least two million cubic feet, formed as the roof of a chamber created by the explosion fell in. Gas has since flowed into the chimney through fractures created by the explosion. Large scale tests of the gas began on June 28 , when production was started at a rate of five million cubic foet a day. After eleven days the well was closed for measurements of temperature and pressure and reopened for four days, flowing at a rate of 0.75 million cubic feet a day. During these last four days the pressure in the chimney increased by between 10 and $20 \mathrm{lb}$ per sq. in. absolute, so the flow of gas into the chimney must exceed the 0.75 million cubic feet a day which was being taken out.

The first gas tapped in June contained 36 per cent of carbon dioxide, believed to have been formed by the decomposition of carbonates during the explosion, but the proportion of carbon dioxide decreased progressively as the proportion of hydrocarbons increased. The gas has been continuously monitored for radioactive isotopes; the explosion should have generated several radionuclides including krypton-85, iodine-131, xenon-133 and tritium. Field tests of small samples of gas taken on January 10 , only a month after the explosion, revealed xenon-133, but this isotope has a half life of only $5 \cdot 3$ days and by June it had disappeared. On the other hand, both krypton-85 and tritium were detected in June but at levels which the AEC claims "do not constitute a health hazard". Samples of gas have been taken to the Lawrence Radiation Laboratory in California for detailed analysis, and a fuller evaluation of the whole project is promised for a meeting of the Society of Petroleum Engineers in Houston in September. It is clear, however, from the preliminary data that the sponsors think Gasbuggy has been a success, and if it lives up to present expectations the technique could more than double the US national reserves of natural gas. Whether or not it proves to be an economically viable method remains to be seen; Gasbuggy has cost about $\$ 4.7$ million.

\section{Planning the Environment}

THE Centre for Environmental Studies (CES) has just produced a report on its first year's work. It is too early yet to see solid results ; the centre's principal effort has been devoted to surveying its domain and deciding which projects to support. It is now sponsoring a wide programme of studies at various institutions and universities in Britain.

When building, transport and habits of work and leisure are allowed to react in an uncontrolled way, the result is a confusion of interests to which the inconvenience of many large cities bears witness. Although the design of cities and transport systems may depend in the last resort on value judgments. the grounds for making such decisions can often be strengthened, and any arbitrary components made to stand out more clearly, by a variety of logical and mathe- matical techniques. The discipline which the CES was founded to promote could broadly be described as the application of operations research to the problems of urban planning. Successful instances of this technique include the transport models worked out for several American cities; the models allow prediction to be made of future trends, on the basis of which action can be taken to invalidate or fulfil the prediction.

The CES was conceived at a conference held in Cambridge in 1965 and sponsored by the British Ministry of Housing and Local Government and the Ford Foundation of New York. With five year grants of $\$ 750,000$ from the Ford Foundation and $£ 600,000$ from the British Government, the centre started work in April 1967. Its purpose is to "promote research and education into the planning and design of the physical environment". A research staff under the direction of A. H. Chilver, professor of civil and municipal engineering at University College, London, has been at work assessing fruitful areas of study.

The centre has now made grants to initiate or continue the support of 17 projects. A three year grant has been made to Sir Leslie Martin and Mr Lionel March at Cambridge University who are studying which forms of building make the most efficient use of land-skyscrapers, happily, are not the only solution. Professor Garnett at Sheffield is looking into the social and economic consequences of setting more stringent limits to pollution of the air and noise. The kind of result that may emerge from this study is a calculation of the rate of return on an investment which reduces pollution levels. The largest single grant, $\mathfrak{E} 45,000$ for three years, has been awarded to Dr Michael Young and Mr Peter Wilmott at the Institute of Community Studies; they are studying the patterns of family work and leisure and the way in which these are relevant to planning.

During its first year the CES has invested $£ 35,000$ in external research. This sum is expected to build up

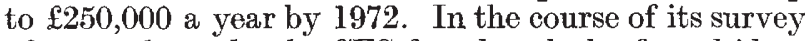
of research needs, the CES found no lack of good ideas to support. Its criteria for investing funds include an assessment of the relevance of a project to major planning problems; studies which are of an essentially development nature are considered to be the concern of government departments and planning authorities.

Besides supporting external research, the centre aims to act as an international forum for the discussion of planning problems. A series of seminars beginning later this year will cover such topics as population growth and movement, leisure activities, and transport studies.

\section{National Parking}

A National Park Day Centre at Brockhole, Windermere, the first of its kind in the country, is to be opened to the public next summer. The centre, owned by the Lake District Planning Board, is in a delightful setting about half-way between the road and the lake on the main Kendal-Keswick road. The gardens and grounds cover 32 acres including 6 acres of woodlands and a third of a mile of lakeshore. At the moment the board is converting the house, which was once a convalescent home, into a centre where visitors to the lakes can go for educational material of all kindsmaps, models, books and exhibits relating to the 